\title{
PENERAPAN MODEL PEMBELAJARAN KOOPERATIF TIPE TGT BERBANTUAN MEDIA AUDIO VISUAL DI SDN-4 PAHANDUT
}

\author{
*' Romianto *2 Rita Rahmaniati * ${ }^{3}$ A'am Rifaldi Khunaifi \\ ' Student in Elementary Teacher Education, Universitas Muhammadiyah Palangkaraya, RTA \\ Milono St. Km. I,5, Palangka Raya, Indonesia. ${ }^{2,3}$ Lecturer in Elementary Teacher Education, \\ Universitas Muhammadiyah Palangkaraya, RTA Milono St. Km. I,5, Palangka Raya, Indonesia. \\ e-mail: rahmaniatirita@gmail.com., e-mail: aamrifaldi@gmail.com
}

\section{ABSTRAK}

Penelitian ini bertujuan untuk: (I) Mendeskripsikan aktivitas belajar peserta didik dengan menggunakan Model Pembelajara Kooperatif Tipe Teams Games Tournament Berbantuan Audio Visual pada kelas IV SDN-4 Pahandut tahun pelajaran 2019/2020. (2) Meningkatkan hasil belajar Matematika peserta didik kelas IV SDN-4 Pahandut tahun pelajaran 2019/2020, dengan menggunakan Model Pembelajaran Kooperatif Tipe Teams Games Tournament Berbantuan audio visual. (3) Mengetahui respon peserta didik terhadap proses pembelajaran kooperatif Teams Games Tournament berbantuan audio visual pada materi pengukuran.

Subjek penelitian ini adalah peserta didik kelas II pada SDN-4 Pahandut. Tahun pelajaran 2019/2020 yang berjumlah 24 orang. Jenis penelitian ini adalah Penelitian Tindakan Kelas (PTK). Teknik pengumpulan data yang digunakan yaitu observasi, tes dan angket. Analisis data yang digunakan yaitu analisis kualitatif dan kuantitatif.Hasil penelitian ini menunjukan bahwa : (I) Aktivitas belajar peserta didik pada proses pembelajaran materi Pengukuran sudut dengan menggunakan model pembelajaran kooperatif tipe Teams Games Tournament berbantuan media audio visual pada kelas IV SDN 4 Pahandut tahun pelajaran 2019/2020 dengan kriteria baik. (2) Ada peningkatan hasil belajar Matematika, hal ini dapat dilihat dari hasil tes awal yang diperoleh peserta didik dengan nilai rata-rata 56,25 dengan ketuntasan klasikal 50\%, mengalami peningkatan pada siklus I yakni memperoleh nilai rata-rata 65 dengan ketuntasan klasikal $75 \%$ dan lebih meningkat pada siklus II yakni memperoleh nilai rata-rata 73,3 dengan ketuntasan klasikal 91,7\%. (3) Respon peserta didik setelah penerapan model pembelajaran kooperatif tipe Teams Games Tournament berbantuan media audio visual pada seluruh pernyataan yaitu 93,67\%, dalam kriteria "tinggi".

\section{Kata Kunci : Model TGT, Audio Visual, Hasil Belajar}

\section{ABSTRACT}

This study aims to: (I) describe the learning activities of students using the Cooperative Learning Model for Audio Visual Assisted Teams Games Tournament in grade IV SDN-4 Pahandut in the 2019/2020 school year. (2) the results of improving Mathematics learning for fourth grade students at SDN-4 Pahandut for the 2019/2020 school year, using the Cooperative Learning Model of the Teams Games Tournament Type with audio-visual Assisted. (3) Knowing the students' responses to the cooperative learning process of the Teams Games Tournament assisted by audio-visuals in measuring the material. The subjects of this study were class II students at SDN-4 Pahandut. The 2019/2020 school year which again recorded 24 people. This type of research is Classroom Action Research (CAR). Data collection techniques used are observation, tests and questionnaires. The data analysis used is qualitative and quantitative analysis. The results of this study indicate that: (I) Students' learning activities in the learning process of measuring angle materials using the Teams Games Tournament type cooperative learning model assisted by audio-visual media in class IV SDN 4 Pahandut for the 2019/2020 school year with good criteria. (2) There is an increase in Mathematics learning outcomes, this can be seen from the results of the initial 
Romianto, Rita Rahmaniati dan A'am Rifaldi Khunaifi, 202I, Penerapan Model Pembelajaran Kooperatif Tipe Tgt Berbantuan Media Audio Visual Di Sdn-4 Pahandut

test obtained by students with an average score of 56.25 with classical completeness of $50 \%$, experiencing an increase in the first cycle, namely obtaining an average score of 65 with classical completeness. $75 \%$ and more increased in the second cycle which obtained an average value of 73.3 with classical completeness of $91.7 \%$. (3) The response of students after the application of the Teams Games Tournament type cooperative learning model assisted by audio-visual media on all statements was $93.67 \%$, in the "high" criteria.

Keywords: TGT Model, Audio Visual, Learning Outcomes 


\section{PENDAHULUAN}

Pendidikan merupakan suatu kebutuhan yang harus dipenuhi dalam kehidupan bermasyarakat, berbangsa, dan bertanah air. Majunya suatu bangsa ditentukan oleh kreativitas pendidikan itu sendiri. Komplikasinya masalah kehidupan menuntut sumber daya manusia yang dapat diandalkan dan mampu berkompetensi, selain pendidikan merupakan wadah kegiatan yang dapat dipandang sebagai pencetak sumber daya manusia yang bermutu tinggi.

Pendidikan Dasar merupakan jenjang pendidikan yang melandasi pendidikan menengah. Adapun tujuan pendidikan di sekolah dasar adalah untuk memperoleh pendidikan dari guru yang memberi pelajaran, meningkatkan potensi belajar serta mengetahu sejauh mana tingkat disiplin belajar peserta didik di sekolah.

Pembelajaran adalah usaha sadar dari guru untuk membuat peserta didik belajar, yaitu terjadi perubahan tingkah laku pada diri peserta didik yang belajar, dimana perubahan itu dengan didapatnya kemampuan baru yang berlaku dalam waktu yang relatif lama. Dalam proses pembelajaran guru mengajarkan beberapa mata pelajaran kepada peserta didik. Mata pelajaran adalah pelajaran yang harus diajarkan (dipelajari) untuk sekolah dasar atau sekolah lanjutan. Salah satu mata pelajaran itu adalah mata pelajaran matematika.

Mata pelajaran matematika di sekolah dasar merupakan salah satu program pengajaran yang bertujuan untuk mempersiapkan peserta didik agar sanggup menghadapi perubahan keadaan didalam kehidupan yang selalu berkembang, melalui latihan bertindak atas dasar pemikiran secara logis, rasional, kritis, cermat, jujur dan efektif dan juga mempersiapkan peserta didik agar menggunakan matematika dan pola pikir matematika dalam kehidupan sehari-hari dan mempelajari berbagai ilmu pengetahuan.
Matematika berfungsi untuk mengembangkan kemampuan menghitung, mengukur, menurunkan dan menggunakan rumus matematika sederhana yang diperlukan dalam kehidupan sehari-hari. Oleh karena itu belajar matematika sangatlah penting bagi peserta didik dari segala jenjang pendidikan, baik sekolah maupun di luar sekolah. Disekolah-sekolah dari TK, SD, SMP, SMA, tentu diajarkan mata pelajaran matematika.

Berdasarkan dari hasil wawancara dengan wali kelas IV SDN 4 Pahadut tahun pelajaran 2019/2020 bahwa Kriteria Ketuntasann Minimal (KKM) dikelas tersebut adalah 65 untuk mata pelajaran matematika. Untuk jumlah peserta didiknya 23 orang peserta didik.

Berdasarkan observasi di

SDN 4 Pahandut, sekolah ini menggunakan kurikulum 2013. hasil ulangan harian peserta didik kelas IV pada semester ganjil tahun ajaran 2019/2020 pada mata pelajaran matematika kurang mencapai Kriteria Ketuntasan Minimal (KKM), dengan KKM pada mata pelajaran matematika yaitu 65 didapati dari 23 orang peserta didik ada 14 orang $60,87 \%$ yang tidak mencapai KKM 65 yang mencapai KKM ada 9 orang peserta didik 39,15\%. Ini terjadi karena pada saat pembelajaran peserta didik kurang aktif, pada saat pembelajaran banyak peserta didik masih bergantung pada guru, dan masih banyak peserta didik yang kesulitan mempelajari materi pada mata pelajaran matematika.

Berdasarkan identifikasi dan batasan masalah, maka rumusan masalah penelitian ini adalah sebagai berikut :

I. Bagaimana aktivitas belajar peserta didik saat menggunakan model pembelajaran kooperatif tipe Teams Games Tournament (TGT) berbantuan media audio visual pada materi pengukuran Sudut? 
2. Apakah ada peningkatan hasil belajar matematika dengan model pembelajaran kooperatif tipe Teams Games Tournament (TGT) berbantuan media audio visual pada peserta didik kelas IV SDN 4 Pahandut?

3. Bagaimana respon peserta didik terhadap proses pembelajaran kooperatif tipe Teams Games Tournament (TGT) berbantuan media audio visual pada materi Pengukuran Sudut?

Menurut Joyce dan Weil dalam (Rusman, 2014 : 133) model pembelajaran adalah suatu rencana atau pola yang dapat digunakan untuk membentuk kurikulum (rencana pembelajaran jangka panjang), merencanakan bahan-bahan pembelajaran, dan membimbing pembelajaran di kelas atau yang lain.

Menurut Cahyaningsih dalam (Isrok'atun \& Rosmala, 2018 : I43) "Model pembelajaran TGT merupakan salah satu model pembelajaran kooperatif yang menggunakan tim kerja dan turnamen, berupa permainan akademik yang dimainkan oleh siswa dengan anggota tim lain untuk menyumbangkan poin bagi skor timnya”. Menurut Slavin dalam (Rusman, 2014 : 225) memiliki ciri-ciri siswa bekerja dalam kelompok-kelompok kecil, memiliki games tournament dan memberikan penghargaan kelompok.

Model TGT ini memerlukan tahapan sebagai jalan berlangsungnya pembelajaran. Empat tahapan dalam model pembelajaran TGT yaitu sebagai berikut Ermilia dalam (Shoimin, 2014 : 205)

I) Presentasi di kelas

Presentasi dikelas merupakan suatu kegiatan belajar menyampaikan materi baik secara langsung ataupu diskusi yang dibimbing oleh guru. Pada tahap awal ini guru menyampaikan tujuan pembelajaran dan juga tata cara kegiatan belajar yang dilakukan peserta didik. Perbedaan prsentasi kelas dengan model pembelajarana kooperatif tipe TGT dengan pengajaran biasa yaitu guru berfokus dalam menjelaskan secara rinci mengenai pembelajaran TGT. Peserta didik akan menyadari pentingnya suatu pemahaman saat presentasi dikelas yang berguna untuk membantu kegiatan turnamen. Dengan demikian, peserta didik berusaha dengan sungguh-sungguh untuk memahami materi yang dipelajari.

2) Belajar Kelompok

Tahap kedua yakni tahap belajar kelompok. Dalam pembelajaran, peserta didik berkelompok untuk memahami materi. Kelompok TGT dibentuk berdasarkan kemampuan dasar akademik peserta didik yakni kemampuan akademik rendah, sedang, dan tinggi. Hal ini bertujuan agar setiap anggota kelompok benar-benar belajar, mempersiapkan, dan membantu setiap anggotanya untuk menjawab soal. Pembelajaran dalam kelompok mencakup pembahasan pemersalahan yang dihadapi Bersama, membandingkan jawaban atau pendapat setiap anggota, serta mengoreksinya apabila terjadi perbedaan hasil. Dengan demikian, terjadi suatu diskusi belajar efektif dalam kelompok untuk saling membantu antaraanggota dalam memahami pelajaran sehingga pada akhirnya dapat menyumbang poin bagi kelompoknya.

3) Turnamen

Turnamen dalam pembelajaran TGT yakni suatu kegiatan berlangsungnya game setelah proses presentasi kelas, dan memahami materi melalui diskusi kelompok. Kegiatan ini dilakukan dengan membagi peserta didik ke dalam beberapa meja turnamen. Setiap anggota kelompok melakukan pertandingan pada meja turnamen yang berbeda. Peserta didik yang memiliki kemampuan akademik yang relative sama pada setiap kelompoknya duduk dalam meja yang sama untuk melakukan turnamen. 
Point turnamen setiap anggota kelompok digabungkan untuk memperoleh skor kelompok. Dengan demikian, setiap anggota bertanding untuk mendapat skor terbaik.

4) Penghargaan

Suatu kelompok akan mendapatkan penghargaan setifikat atau bentuk penghargaan lain apabila mencapai poin sesaui kriteria tertentu. Penghargaan ini penting untuk memberikan pengertian bahwa keberhasilan kelompok diperoleh dari keberhasilan semua anggota kelompok. Hal ini memunculkan motivasi belajar untuk saling membantu anggota kelompok dalam memahami materi yang sedang dipelajari.

\section{Kelebihan Model Pembelajaran Teams Games Tournament (TGT)}

Kegiatan pada model pembelajaran TGT berpusat pada peserta didik sehingga memiliki beberapa kelebihan sebagai berikut Wijaya dalam (Isrok'atun \& Rosmala, 2018 : I45).

I) Semua peserta didik memiliki kesempatan untuk mengemukakan pendapat atau memperoleh pengetahuan dari diskusi kelompok.

2) Saling menghargai di antara peserta didik.

3) Peserta didik mendapatkan keterampilan bekerja sama.

4) Menumbuhkan keberanian dan membiasakan bersaing sportif.

5) Menumbuhkan keaktifan peserta didik.

\section{Kekurangan Model Pembelajaran Teams Games Tournament (TGT)}

Selain terdapat kelebihan, model pembelajaran TGT memili kekurangan, di antaranya sebagai berikut (Isrok'atun \& Rosmala, 2018 : 146).

1) Penggunaan waktu yang relatif lama dan biaya besar.
2) Jika kemampuan guru sebagai motivator dan fasilidator kurang memadai atau sarana tidak cukup tersedia, maka pembelajaran TGT sulit dilakukan.

3) Penerapan model pembelajaran TGT juga memiliki kelemahan bagi peserta didik dalam mentransfer pengetahuan kepada peserta didik lain.

Kata media berasal dari Bahasa Latin medius secara harfiah berarti 'tengah', 'perantara' atau 'pengantar'. Dalam Bahasa Arab, media adalah perantara (wasaa'ill) atau pengantar pesan dari pengirim kepada penerima pesan.

Arsyad (2017:3) menyatakan bahwa "media dalam proses belajar mengajar cendrung diartikan sebagai alatalat grafis, photografis, atau elektronis untuk menangkap, memperoses atau menyusun kembali informasi visual atau verbal.

Meurut Gagne dalam (Sanjaya, 2012 : 60) mengatakan bahawa "Media pembelajaran adalah berbagai komponen yang ada dalam lingkungan peserta didik yang dapat merangsang untuk belajar”.

Menurut Sanjaya (2012 : 109-110) media audio visual yaitu jenis media yang selain mengandung unsur gambar yang bisa dilihat, misalnya rekaman video, film, slide suara, dan sebagainya.

Menurut Isrok'atun dan Rosmala (2018 : 3) Matematika merupakan suatu ilmu yang mempelajari bagaimana proses berpikir secara rasional dan masuk akal dalam memperoleh konsep. Matematika dikatakan sebagai suatu ilmu karena keberadaanya dapat dipelajari dari fenomena.

Menurut Arikunto (20I4: II0) mengatakan bahwa "Hipotesis merupakan suatu jawaban yang bersifat sementara terhadap permasalahan penelitian, sampai terbukti melalui data yang terkumpul."

Berdasarkan pendapat diatas, maka penelitian ini dapat di hipotesiskan: 
I. Aktivitas belajar baik dalam proses pembelajaran matematika dengan menggunakan model pembelajaran Kooperatif Tipe Teams Games Tournament (TGT) berbantuan media audio visual pada peserta didik SDN 4 Pahandut Tahun Pelajaran 2019/2020.

2. Adanya Peningkatan hasil belajar matematika dengan menggunakan model pembelajaran Kooperatif Tipe Teams Games Tournament (TGT) berbantuan media audio visual pada peserta didik SDN 4 pahandut.

3. Respon peserta didik sedang terhadap pembelajaran dengan menggunakan model pembelajaran kooperatif tipe Teams Games Tournament (TGT) berbantuan media audio visual.

\section{METODOLOGI PENELITIAN}

Penelitian ini dilaksanakan pada bulan November sampai bulan Maret tahun pelajaran 2019/2020. Penelitian ini dilaksanakan di kelas IV di SDN 4 Pahandut, yang berlokasikan di Jl. Kapten Hasanudin kec.Pahandut Palangka Raya. Alasan penelitian di sekolah ini karena ada fenomena yang berada di sekolah sesuai dengan penelitian.

Penelitian ini menggunakan Penelitian Tindakan Kelas (PTK).

Sedangkan menurut Wahidmuri dan Ali (Diplan \& Setiawan, 2018 : 14) bahwa "Penelitian tindakan kelas diartikan sebagai upaya atau tindakan dilakukan oleh guru atau peneliti untuk memecahkan masalah pembelajaran atau penelitian".

Kehadiran peneliti tindakan kelas ini adalah sebagai bentuk dari tujuan dari sebuah tindakan yang dimana menemukan permasalah yang dikelas untuk memberikan solusi. Peneliti juga berperan mengumpulkan dan menganalisis data serta sebagai pelapor hasil penelitian.

Subjek penelitian pada penelitian tindakan kelas ini adalah seluruh peserta didik kelas IV SDN 4 Pahandut Tahun Pelajaran yang berjumlah 23 orang dan dijelaskan pada Tabel 4.

Tabel 4

Subjek Penelitian

\begin{tabular}{|l|l|l|l|}
\hline \multirow{2}{*}{ Kelas } & \multicolumn{2}{|l|}{ Jenis Kelamin } & \multirow{2}{*}{ Jumlah } \\
\cline { 2 - 4 } & $\begin{array}{l}\text { Laki- } \\
\text { laki }\end{array}$ & Perempuan & \\
\hline IV & $\mathbf{7}$ & $\mathbf{1 6}$ & $\mathbf{2 3}$ \\
\hline
\end{tabular}

Sumber: wali kelas IV SDN- 4 Pahandut Pelajaran 20 19/2020

Pengumpulan data yang digunakan oleh peneliti dalam penelitian ini adalah obsevasi, tes, dan angket. Tes digunakan untuk memperoleh data kuantitatif, sedangkan observasi dan angket untuk memperoleh data kualitatif.

Tabel 19

Rekapitulasi Data Observasi

Aktivitas Guru

\begin{tabular}{|l|l|l|l|}
\hline & $\begin{array}{l}\text { Jumlah } \\
\text { Skor }\end{array}$ & $\begin{array}{l}\text { Skor } \\
\text { Rata- } \\
\text { rata }\end{array}$ & Kategori \\
\hline $\begin{array}{l}\text { Siklus } \\
\text { I }\end{array}$ & 66 & 3,3 & Baik \\
\hline $\begin{array}{l}\text { Siklus } \\
\text { II }\end{array}$ & 71,5 & 3,58 & Baik \\
\hline
\end{tabular}

Tabel 20

Rekapitulasi Data Observasi Aktivitas Peserta Didik

\begin{tabular}{|l|l|l|l|}
\hline & $\begin{array}{c}\text { Jumlah } \\
\text { Skor }\end{array}$ & $\begin{array}{l}\text { Skor } \\
\text { Rata- } \\
\text { rata }\end{array}$ & Kategori \\
\hline Siklus I & 66 & 3,3 & Baik \\
\hline Siklus II & $7 I, 5$ & 3,58 & Baik \\
\hline
\end{tabular}

\section{Aktivitas Guru dan}

Peserta didik

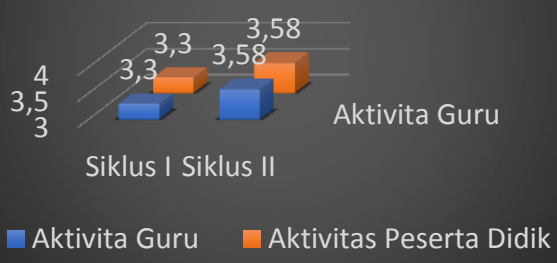

Gambar 10 Aktivitas Guru dan Peserta Didik 
Perbandingan hasil belajar Matematika pada materi pengukuran sudut antara pra siklus, setelah siklus I, setelah siklus II sebagai berikut :

Tabel 2 I

Hasil Belajar Peserta Didik Pada Tes Awal dan Tes Akhir

\begin{tabular}{|l|l|l|l|}
\hline No & Data & $\begin{array}{l}\text { Persentase } \\
\text { Ketuntasan } \\
\text { Klasikal }\end{array}$ & $\begin{array}{l}\text { Nilai } \\
\text { Rata- } \\
\text { rata }\end{array}$ \\
\hline I & $\begin{array}{l}\text { Observasi } \\
\text { Awal }\end{array}$ & $50 \%$ & 56,25 \\
\hline 2 & $\begin{array}{l}\text { Tes Akhir } \\
\text { Siklus I }\end{array}$ & $75 \%$ & 65 \\
\hline 3 & $\begin{array}{l}\text { Tes Akhir } \\
\text { Siklus II }\end{array}$ & $91,7 \%$ & 73,3 \\
\hline
\end{tabular}

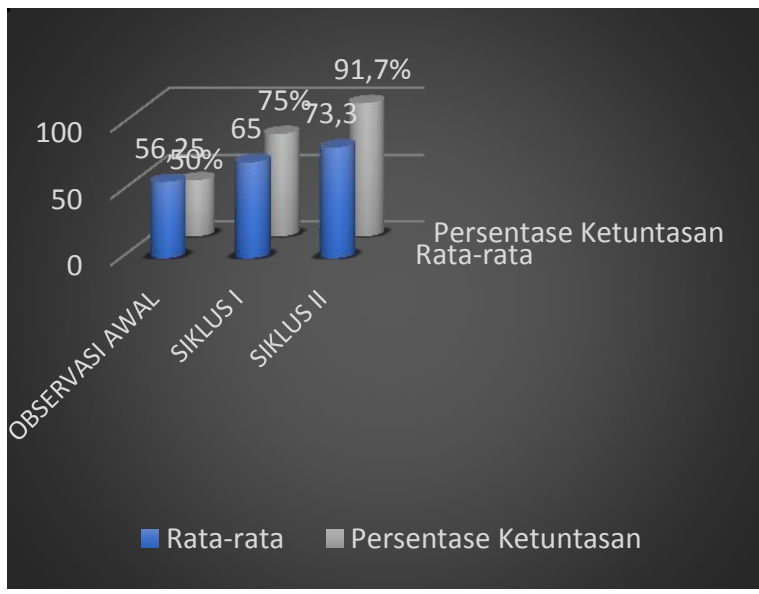

\section{Gambar I I}

Ketuntasan Hasil Belajar Peserta Didik

Berdasarkan hasil tabel di atas terlihat bahwa sebelum dilakukan siklus I persentase hasil belajar sebesar $50 \%$, setelah dilakukan siklus I persentase hasil belajar sebesar $75 \%$ dan persentase hasil belajar pada siklus II adalah 91,7\%, sehingga ada peningkatan hasil belajar peserta didik dari sebelum perlakuan sampai siklus II.

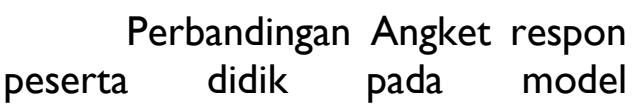

pembelajaran kooperatif tipe Teams

Games Tournament berbantuan media audio visual pada materi penguuran sudut.
Tabel 22

Tabel Angket Respon Peserta Didik Siklus I dan II

\begin{tabular}{|c|c|c|c|c|c|c|c|}
\hline \multirow{2}{*}{$\begin{array}{l}\mathrm{K} \\
\mathrm{o} \\
\mathrm{d} \\
\mathrm{e} \\
\mathrm{N} \\
\mathrm{o} \\
\mathrm{m} \\
\mathrm{o} \\
\mathrm{r}\end{array}$} & \multirow[b]{2}{*}{$\begin{array}{l}\text { Pernyata } \\
\text { an }\end{array}$} & & Alter & atif $P$ & ihan & & \multirow[t]{2}{*}{$\begin{array}{l}\text { Pres } \\
\text { enta } \\
\text { se }\end{array}$} \\
\hline & & SS & ST & $R G$ & TS & $\begin{array}{l}\mathrm{S} \\
T \\
S\end{array}$ & \\
\hline $\begin{array}{l}P \\
P\end{array}$ & $\begin{array}{l}\text { Saya } \\
\text { sangat } \\
\text { bersema } \\
\text { ngat } \\
\text { belajar } \\
\text { dengan } \\
\text { menggun } \\
\text { akan } \\
\text { model } \\
\text { pembelaj } \\
\text { aran } \\
\text { kooperat } \\
\text { if tipe } \\
\text { TGT } \\
\text { berbantu } \\
\text { an media } \\
\text { audio } \\
\text { visual. }\end{array}$ & $\begin{array}{l}88 \\
\%\end{array}$ & $8 \%$ & $0 \%$ & $0 \%$ & $\begin{array}{l}4 \\
\%\end{array}$ & $95 \%$ \\
\hline $\begin{array}{l}P \\
2\end{array}$ & $\begin{array}{l}\text { Belajar } \\
\text { dengan } \\
\text { menggun } \\
\text { akan } \\
\text { model } \\
\text { pembelaj } \\
\text { aran } \\
\text { kooperat } \\
\text { if tipe } \\
T G T \\
\text { berbantu } \\
\text { an media }\end{array}$ & $\begin{array}{l}79 \\
\%\end{array}$ & $\begin{array}{l}17 \\
\%\end{array}$ & $4 \%$ & $0 \%$ & $\begin{array}{l}0 \\
\%\end{array}$ & $95 \%$ \\
\hline
\end{tabular}


Romianto, Rita Rahmaniati dan A'am Rifaldi Khunaifi, 202I, Penerapan Model Pembelajaran Kooperatif Tipe Tgt Berbantuan Media Audio Visual Di Sdn-4 Pahandut

\begin{tabular}{|c|c|c|c|c|c|c|c|c|c|c|c|c|c|c|c|}
\hline & \begin{tabular}{|l|} 
audio \\
visual \\
menyena \\
ngkan.
\end{tabular} & & & & & & & & \multirow{2}{*}{$\begin{array}{l}\text { didik } \\
\text { menjadi } \\
\text { berperan } \\
\text { aktif } \\
\text { dalam } \\
\text { kelompo } \\
\text { k dan } \\
\text { tidak } \\
\text { hanya } \\
\text { bergantu } \\
\text { ng } \\
\text { dengan } \\
\text { guru. } \\
\end{array}$} & & & & & & \\
\hline $\begin{array}{l}P \\
3\end{array}$ & \begin{tabular}{|l|} 
Setelah \\
belajar \\
dengan \\
model \\
$T G T$ \\
berbantu \\
an media \\
audio \\
visual
\end{tabular} & & & & & & & & & & & & & & \\
\hline (d) & $\begin{array}{l}\text { membuat } \\
\text { saya rajin } \\
\text { belajar } \\
\text { dan } \\
\text { meningka } \\
\text { tkan rasa } \\
\text { ingin } \\
\text { tahu } \\
\text { saya. }\end{array}$ & $\begin{array}{l}66 \\
\%\end{array}$ & $\begin{array}{l}17 \\
\%\end{array}$ & $\begin{array}{l}17 \\
\%\end{array}$ & $0 \%$ & $\begin{array}{l}0 \\
\%\end{array}$ & $90 \%$ & $\begin{array}{l}P \\
6\end{array}$ & \begin{tabular}{|l} 
Belajar \\
menggun \\
akan \\
model \\
$T G T$ \\
berbantu \\
an media \\
audio \\
visual
\end{tabular} & 71 & 29 & $0 \%$ & $0 \%$ & 0 & 94,1 \\
\hline $\begin{array}{l}P \\
4\end{array}$ & $\begin{array}{l}\text { Menggun } \\
\text { akan } \\
\text { model } \\
T G T \text { saya } \\
\text { lebih } \\
\text { percaya } \\
\text { diri }\end{array}$ & & & & & & & & $\begin{array}{l}\text { dapat } \\
\text { meningka } \\
\text { tkan } \\
\text { kemamp } \\
\text { uan } \\
\text { berpikir } \\
\text { saya. }\end{array}$ & $\%$ & $\%$ & $0 \%$ & $0 \%$ & $\%$ & $7 \%$ \\
\hline 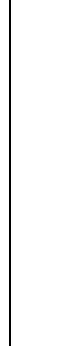 & $\begin{array}{l}\text { dalam } \\
\text { menyam } \\
\text { paikan } \\
\text { pendapat } \\
\text { dalam } \\
\text { kelompo } \\
\text { k. }\end{array}$ & $\begin{array}{l}79 \\
\%\end{array}$ & $\begin{array}{l}21 \\
\%\end{array}$ & $0 \%$ & $0 \%$ & $\begin{array}{l}0 \\
\%\end{array}$ & $\begin{array}{l}95,8 \\
3 \%\end{array}$ & $\mid \begin{array}{l}P \\
7\end{array}$ & $\begin{array}{l}\text { Model } \\
T G T \\
\text { berbantu } \\
\text { an media } \\
\text { audio } \\
\text { visual } \\
\text { dilakukan }\end{array}$ & & & & & & \\
\hline $\begin{array}{l}\mathrm{P} \\
5\end{array}$ & $\begin{array}{l}\text { Belajar } \\
\text { menggun } \\
\text { akan } \\
\text { model } \\
T G T \\
\text { berbantu } \\
\text { an media } \\
\text { audio } \\
\text { visual } \\
\text { membuat } \\
\text { saya }\end{array}$ & $\begin{array}{l}75 \\
\%\end{array}$ & $\begin{array}{l}21 \\
\%\end{array}$ & $4 \%$ & $0 \%$ & $\begin{array}{l}0 \\
\%\end{array}$ & $\begin{array}{c}94,1 \\
7 \%\end{array}$ & & $\begin{array}{l}\text { berkelo } \\
\text { mpok } \\
\text { membuat } \\
\text { saya } \\
\text { dapat } \\
\text { bertukar } \\
\text { pendapat } \\
\text { sesama } \\
\text { anggota } \\
\text { kelompo } \\
\text { k. }\end{array}$ & $\begin{array}{l}79 \\
\%\end{array}$ & $\begin{array}{c}2 \\
8 \%\end{array}$ & $\begin{array}{l}3 \\
13 \\
\%\end{array}$ & $\begin{array}{c}0 \\
0 \%\end{array}$ & $\begin{array}{l}0 \\
0 \\
\%\end{array}$ & $\begin{array}{c}93,3 \\
\%\end{array}$ \\
\hline
\end{tabular}




\begin{tabular}{|c|c|c|c|c|c|c|c|}
\hline $\begin{array}{l}P \\
8\end{array}$ & $\begin{array}{l}\text { Belajar } \\
\text { dengan } \\
\text { model } \\
\text { TGT } \\
\text { berbantu } \\
\text { an media } \\
\text { audio } \\
\text { visual } \\
\text { mengem } \\
\text { bangkan } \\
\text { sikap } \\
\text { peduli } \\
\text { saya } \\
\text { dengan } \\
\text { teman } \\
\text { dan } \\
\text { sesama } \\
\text { manusia. }\end{array}$ & $\begin{array}{l}63 \\
\%\end{array}$ & $\begin{array}{l}37 \\
\%\end{array}$ & $0 \%$ & $0 \%$ & $\begin{array}{l}0 \\
\%\end{array}$ & $\begin{array}{c}92,5 \\
\%\end{array}$ \\
\hline $\begin{array}{l}P \\
9\end{array}$ & $\begin{array}{l}\text { Belajar } \\
\text { dengan } \\
\text { model } \\
T G T \\
\text { berbantu } \\
\text { an media } \\
\text { audio } \\
\text { visual } \\
\text { melatih } \\
\text { saya } \\
\text { percaya } \\
\text { dengan } \\
\text { kelompo } \\
\text { k. }\end{array}$ & $\begin{array}{l}54 \\
\%\end{array}$ & $\begin{array}{l}46 \\
\%\end{array}$ & $0 \%$ & $0 \%$ & $\begin{array}{l}0 \\
\%\end{array}$ & $\begin{array}{c}90,8 \\
3 \%\end{array}$ \\
\hline $\begin{array}{l}P \\
I \\
0\end{array}$ & $\begin{array}{l}\text { Dengan } \\
\text { menggun } \\
\text { akan } \\
\text { model } \\
\text { pembelaj } \\
\text { aran } \\
\text { kooperat } \\
\text { if tipe } \\
\text { TGT } \\
\text { berbantu } \\
\text { an media } \\
\text { audio } \\
\text { visual } \\
\text { memuda } \\
\text { hkan } \\
\text { saya } \\
\text { untuk }\end{array}$ & $\begin{array}{l}79 \\
\%\end{array}$ & $\begin{array}{l}21 \\
\%\end{array}$ & $0 \%$ & $0 \%$ & $\begin{array}{l}0 \\
\%\end{array}$ & $\begin{array}{c}95,8 \\
3 \%\end{array}$ \\
\hline
\end{tabular}

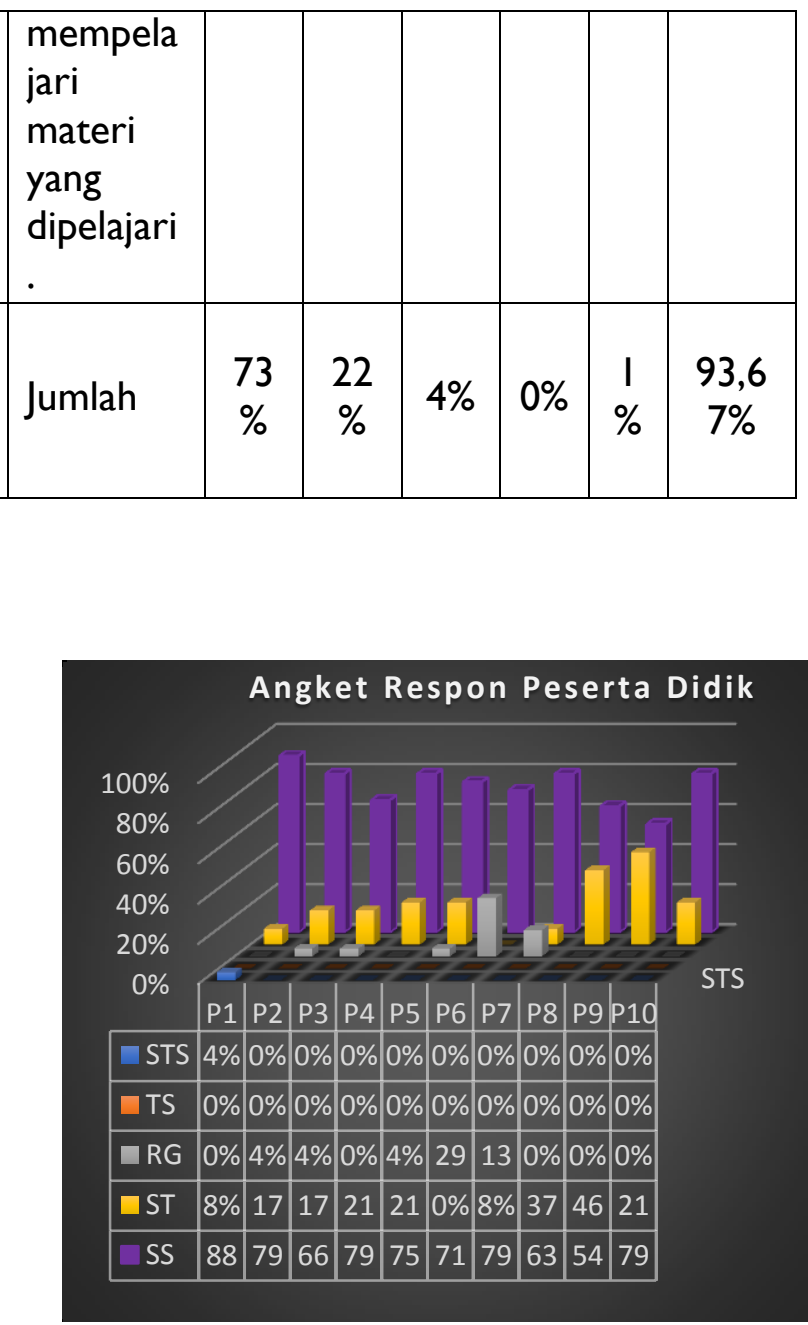

\section{Gambar 12}

\section{Respon Peserta didik}

Berdasarkan hasil tabel di atas terlihat bahwa persentase hasil angket respon peserta didik yang menjawab Sangat Setuju ada 176 orang atau persentase $73 \%$ hasil, Peserta didik yang menjawab Setuju (ST) ada 52 orang atau presentase $22 \%$, ada 9 orang peserta didik yang menjawab Ragu-ragu (RR) presentase 4\%, tidak ada yang menjawab dan presentase $0 \%$, ada I orang peserta didik yang menjawab sangat tidak setuju dan presentase $1 \%$. Persentase respon peserta didik pada seluruh pernyataan yaitu 93,67\%, dan merupakan termasuk dalam kriteria "tinggi".

\section{Simpulan}


Berdasarkan hasil penelitian, maka dapat disimpulkan beberapa hal sebagai berikut :

1. Aktivitas belajar peserta didik pada pembelajaran matematika pada materi pengukuran sudut dengan menggunakan model pembelajaran kooperatif tipe Teams Games Tornament berbantuan media audio visual dengan kriteria baik.

2. Ada peningkatan hasil belajar matematika pada materi pengukuran sudut dengan menggunakan model pembelajaran kooperatif tipe Teams Games Tournament berbantuan media audio visual.

3. Respon peserta didik terhadap penerapan model pembelajaran kooperatif tipe Teams Games Tournament berbantuan media audio visual pada materi pengukuran sudut dalam kriteria respon "tinggi".

\section{DAFTAR PUSTAKA}

Arikunto, S. (20I4). Prosedur Penelitian. Jakarta: Rineka Cipta.

Arsyad, A. (2017). Media Pembelajaran. Jakarta: PT RajaGrafindo Persada

Isrok'atun, \& Rosmala, A. (2018). Modelmodel Pembelajaran Matematika. Jakarta: PT Bumi Aksara.

Rusman. (20l4). Model-model Pembelajaran. Jakarta: PT Rajagrafindo Persada.

Sanjaya, W. (20/2). Media Komunikasi Pembelajaran. Jakarta: Kencana Pranada Media Group.

Shoimin, A. (20I4). 68 Model Pembelajaran Onovatif dalam Kurikulum 2013. Yogyakarta: Ar-Ruzz Media.

Diplan, \& Setiawan, M. A. (2018). Penelitian Tindakan Kelas Teori Serta Panduan Bagi Guru Kelas dan Guru Bimbingan Konseling. Yogyakarta: Deepublish. 